\title{
Erratum to: Management of complication from temporal bone fractures
}

Ljiljana Cvorovic • Milan B. Jovanovic • Marko Markovic · Zoran Milutinovic • M. Strbac

Published online: 28 August 2011

(C) Springer-Verlag 2011

Erratum to: Eur Arch Otorhinolaryngol

DOI 10.1007/s00405-011-1641-8

Unfortunately, the first name of the corresponding author in the online published article is swapped. The correct first name is Ljiljana and the last name is Cvorovic.

The online version of the original article can be found under doi:10.1007/s00405-011-1641-8.

L. Cvorovic $(\bowtie) \cdot$ M. B. Jovanovic · Z. Milutinovic · M. Strbac Department of Otorhinolaryngology and Maxillofacial Surgery, Clinical Hospital Centre "Zemun", Medical School,

University of Belgrade, Vukova 9, 11080 Belgrade, Serbia

e-mail: 1jiljanamil@sezampro.rs

M. Markovic

Department of Neurosurgery, Clinical Hospital Centre,

"Zemun", Medical School, University of Belgrade,

Belgrade, Serbia 